\title{
CLIENTES COM DOENÇA RENAL CRÔNICA: AVALIAÇÃO DE ENFERMAGEM SOBRE A COMPETÊNCIA PARA O AUTOCUIDADO
}

\author{
Clients with Chronic Renal Disease: Nursing Evaluation about \\ the Competence for the Selfcare \\ Clientes con Enfermedad Renal Crónica: Evaluación de Enfermería \\ Sobre la Competencia para el Auto-cuidado
}

Gilvanice de Sousa Pacheco

Iraci dos Santos

Rachel Bregman

\begin{abstract}
Resumo
0 ingresso em terapias dialíticas em condições inadequadas demanda desconfor to e sofrimento aos clientes com doença renal crônica (DRC), além de custos ao sistema de saúde e do trabalho de enfermagem. Visando incentivar o cliente para a adesão ao tratamento conservador dessa patologia, tem-se como objetivo: avaliar a competência e o déficit para o autocuidado do cliente com DRC. Implementou-se o método epidemiológico mediante entrevista com 51 clientes do ambulatório de uremia do HUPE/UERJ), em 2005. Evidenciou-se o déficit do conhecimento sobre as conseqüências da hipertensão arterial e diabetes associados à DRC e os limites na escolha e adesão das terapêuticas médica, nutricional e de enfermagem. Concluiu-se que dúvidas sobre essa doença permeiam a vida dos clientes e podem interferir na adesão ao tratamento e comprometer sua qualidade de vida. Esse achado reforça a importância do ensino do autocuidado para demonstrar seu potencial para enfrentar a DRC.
\end{abstract}

Palavras-chave: Enfermagem. Insuficiência Renal Crônica. Autocuidado.

\begin{abstract}
The admission in dialysis therapies in inappropriate conditions demand discomfort and suffering to the clients with chronicle renal disease (CRD), besides the cost to the health system and of the nursing work. Aim to encourage the client for the adhesion to the treatment that preserves this pathology, it has as objective: to evaluate the competency and the deficit to the self care of the client with CRD. It was implanted the epidemiologic method trough interviews with 51 clients of the clinics of uremia of the HUPE/UERJ, in 2005. It became evident the deficit of the knowledge about the consequences of the arterial hypertension and diabetes linked to the CRD and the limits in the choice and adhesion of the medical therapies, nutritional and of nursing. It was conclude that the doubts about this disease, permeates the life of the clients and may interfere in the adhesion to the treatment and to compromise the client's quality of life. This found it is a reinforcement to the importance of the self care learning to demonstrate its potential to face the CRD.
\end{abstract}

\section{Keywords:}

Nursing. Chronicle Renal Insufficiency. Self Care.

\section{Resumen}

El ingreso en terapias dialíticas en condiciones inadecuadas demanda incomodidad y sufrimiento a los clientes con enfermedad renal crónica (ERC), allende costas al sistema de salud y del trabajo de enfermería. Teniendo en vista incentivar el cliente para la adhesión al tratamiento conservador de esta patología, se objetiva: evaluar la competencia y el déficit para el auto cuidado del cliente con ERC. Implementóse el método epidemiológico por entrevista con 51 clientes del ambulatorio de uremia del HUPE/UERJ, en 2005. Evidencióse el déficit del conocimiento sobre las consecuencias de la hipertensión arterial y diabetes asociados a la ERC y los limites en la elección y adhesión de las terapéuticas médica, nutricional y de enfermería. Concluyese que dudas sobre esa enfermedad atravesan la vida de los clientes y poden interferir en la adhesión al tratamiento y comprometer su cualidad de vida. Ese hallado refuerza la importancia de la enseñanza del auto cuidado para demostrar su potencial para enfrentar la ERC.

Palabras clave:

Enfermería. Insuficiencia Renal Crónica. Auto Cuidado. 


\section{INTRODUÇÃO}

0 cliente iniciante em um programa de diálise é submetido a muitas mudanças em seu cotidiano, tais como cuidados com a dieta, controle da ingestão de líquidos, cuidados com a fístula arteriovenosa, além da necessidade de seguir um programa terapêutico delimitado por uma escala para cujos dias aprazados é imprescindível seu comparecimento e adesão. Todas essas mudanças geram estresse e desencadeiam sentimentos de revolta e conflito nessas pessoas, os quais interferem na adesão à sua terapia.

Entende-se, então, a importância de se oferecer e desenvolver um programa de orientação e educação para que o cliente tenha consciência de sua doença renal, do autocuidado e escolha da terapia de substituição renal quando ainda se encontra na fase inicial da doença, acompanhado pelo tratamento conservador.

\section{OBJ ETO DE ESTUDO E OBJ ETIVOS}

Com a implementação do programa de orientação e educação para o autocuidado, pretende-se diminuir a ansiedade do cliente a respeito do seu tratamento e estimular seu interesse para o autocuidado e, conseqüentemente, a maior adesão ao tratamento, com a intenção de torná-lo membro ativo do processo saúdedoença e responsável por sua qualidade de vida.

Nesse contexto, sobreleva-se a concepção de promoção da saúde explicitada na Carta de Ottawa, adotada durante a primeira Conferência Internacional sobre Promoção de Saúde 1 . Esse documento define promoção de saúde como o processo de oferecer à população capacidade de implementar o controle sobre sua saúde e de melhorá-la, e ressalta que a promoção da saúde ajuda no desenvolvimento individual e social oferecendo informações, assegurando a educação para a saúde e aperfeiçoando atitudes indispensáveis à vida, e, dessa forma, permitindo às pessoas aprenderem e terem controle sobre sua situação.

0 intuito, portanto, é propiciar as vantagens referidas, inclusive lembrando da afirmação de que 2:311: o cuidado prestado ao cliente em insuficiência renal irreversível na fase de tratamento conservador, estágio da doença que antecede a falência total do rim, é pouco discutido se comparado com o tratamento dialítico ou transplante renal.

Do mesmo modo, ressalte-se o compromisso social do enfermeiro para com a sociedade que se concretiza na sua prática social interligada à técnico-científica, administrativa e de pesquisa, junto aos clientes em regime de internação ou não. Aqui destaca-se esta prática lembrando-se que ${ }^{3: 123:}$ o enfermeiro que educa para o autocuidado desenvolve um papel diretamente político ao facilitar a autonomia de grupos sociais (...).

Neste trabalho, reforça-se que a atuação do enfermeiro como educador do cliente com doença renal crônica é indispensável, pois o mesmo é responsável pelas orientações sobre o autocuidado, tornando-o membro ativo no processo saúde-doença. Nesse processo educativo é essencial que 0 indivíduo seja respeitado em sua totalidade, ou seja, holisticamente dentro do complexo biopsicossocial.

Para desenvolver essa prática educativa, o enfermeiro necessita ter, além da fundamentação científica e da competência técnica, conhecimentos dos aspectos que levam em consideração os sentimentos, as necessidades e desejos dos clientes sob sua orientação ${ }^{4}$. Assim, o papel do enfermeiro é de grande colaboração na tentativa de ajudá-los a adaptarse a um novo estilo de vida.

0 desempenho deste papel ressalta a responsabilidade do enfermeiro, como membro de uma equipe multidisciplinar, ao identificar os problemas de saúde do cliente com doença renal e tentando resolvê-los, junto com ele, mediante uma assistência de enfermagem que proporcione a esta pessoa uma melhor qualidade de vida².

Ainda sobre a prática social e educativa, concorda-se com a seguinte concepção ${ }^{5: 86}$ : será a partir da situação presente, existencial, concreta, refletindo o conjunto de aspirações do povo, que poderemos organizar o conteúdo programático da educação ou da ação política. A partir dela determinou-se como objeto de estudo: a avaliação de enfermagem sobre a competência para o autocuidado.

Neste trabalho, destaca-se como objetivo: avaliar a competência e o déficit para o autocuidado do cliente com DRC.

\section{MÉTODO}

Escolheu-se o método descritivo, para identificar as expectativas dos sujeitos sobre o tratamento e competência para se autocuidar. 0 referido método consistiu na quantificação de dados através da estatística descritiva, visando o estudo de fatos que se relacionam à compreensão de fatores determinantes para evolução do processo saúde/doença ${ }^{6}$.

Após aprovação do Comitê de Ética do Hospital Universitário Pedro Ernesto da Universidade do Estado do Rio de Janeiro (HUPE/UERJ), iniciou-se a pesquisa mediante a técnica de observação indireta através da entrevista orientada por formulário, estruturando-se o instrumento de coleta de dados com questões objetivas.

Foram entrevistados, em 2005, 51 clientes com DRC em tratamento conservador, acompanhados pela equipe multiprofissional, no ambulatório de uremia da disciplina de nefrologia desta instituição. Em cumprimento às normas éticas de pesquisa em seres humanos, essas pessoas foram convidadas e concordaram em participar da investigação, após ciência dos riscos e benefícios da mesma. Ressalte-se que as entrevistas ocorreram no ambulatório de uremia durante o horário de atendimento, ou seja, na pré ou pós-consulta de saúde.

Foram selecionadas como variáveis do estudo: conhecimento sobre DRC quanto a: funções dos rins, complicações da hipertensão arterial sistêmica e diabetes melito, hábitos de vida para manter PA e controlar a glicemia, modalidade e periodicidade de exercício físico praticado, ocorrência da anemia e doença óssea associadas à DRC.

Os dados obtidos na entrevista através do formulário foram tabulados pelo programa Microsoft Excel ${ }^{\circledR}$, tratados estatisticamente por freqüência absoluta e percentual, representados em tabelas e descritos em linguagem numérica. 


\section{RESULTADOS}

\section{Conhecimento dos sujeitos sobre HAS e Diabetes}

Constatou-se sobre o conhecimento dos clientes que: 41 $(80,39 \%)$ clientes responderam que a hipertensão compromete o coração, 41 (80,39\%) clientes responderam que compromete os rins, $48(94,12 \%)$ clientes responderam que pode causar derrame, nenhum cliente marcou a opção D (não acontece nada), e, para a opção "outros", obtivemos as seguintes respostas: $1(1,96 \%)$ perda da visão e $1(1,96 \%)$ falta de ar. Entende-se que, a partir desses resultados, a maioria dos clientes tem noção das complicações ocasionadas pelo não-controle da HAS, sendo a complicação mais conhecida o AVC, comumente designado como "derrame"; entretanto, percebe-se que 10 clientes desconhecem a doença renal como conseqüência da hipertensão (Tabela 1).

\section{Tabela}

Complicações da hipertensão arterial sistêmica, segundo informações dos clientes. Ambulatório de uremia. HUPE/UERJ. Rio de Janeiro, 2005.

\begin{tabular}{l|c|c|c|c|c|c}
\hline \multirow{2}{*}{ Complicações } & \multicolumn{2}{|c|}{ SIM } & \multicolumn{2}{c|}{ NÃO } & \multicolumn{2}{c}{ TOTAL } \\
\cline { 2 - 7 } & $\mathrm{N}$ & $\%$ & $\mathrm{~N}$ & $\%$ & $\mathrm{~N}$ & $\%$ \\
\hline Cardiopatia & 41 & 80,39 & 10 & 19,61 & 51 & 100 \\
Doença renal & 41 & 80,39 & 10 & 19,61 & 51 & 100 \\
AVC & 48 & 94,12 & 3 & 5,88 & 51 & 100 \\
\hline
\end{tabular}

A hipertensão arterial provoca uma agressão mecânica ao sistema cardiovascular e renal que refletem o alto risco que apresentam os clientes a desenvolver vasculopatias graves, tais como as coronariopatias (como exemplo, angina e infarto do miocárdio) e os acidentes vasculares cerebrais. A hipertrofia cardíaca, conseqüência da maior quantidade de trabalho mecânico realizado pelo coração quando a pressão arterial está elevada, pode ocasionar a insuficiência cardíaca. Outra complicação é a doença renal crônica devida à exposição do tecido renal durante muitos anos a altas pressões de perfusão, acarretando fibrose crônica do parênquima renal e a perda irreversível da função desse órgão 7,8 .

Nesta pesquisa, os principais sintomas citados pelos clientes quando estão com a pressão arterial alta são tontura, $12(23,53 \%)$, e cefaléia, $11(21,57 \%)$. Além destes sintomas apresentados na tabela, identificaram-se outros sintomas relatados de forma subjetiva por 11 clientes, os quais são: dor na nuca, visão turva, sensação de levitação, formigamento nas mãos, enjôo, sangramento pelo nariz, "agonia na cabeça", "sangue fervendo no corpo" e "coração batendo no ouvido". Portanto, deve-se ouvir com muita atenção a queixa do cliente quanto a esses sintomas, haja vista que pode indicar que 0 cliente não está seguindo a dieta ou tomando os medicamentos, ou mesmo a necessidade de adequação da dose da medicação, ou ainda que o cliente pode estar sofrendo problemas psicossociais (dificuldades financeiras, problemas familiares, negação da doença), os quais estão influenciando no controle da pressão arterial.

É importante ressaltar que na maioria dos indivíduos a hipertensão arterial é absolutamente assintomática. Por isso, esses clientes devem ser orientados também quanto à importância da monitorizarão da pressão arterial, que pode ser feita não só durante a consulta médica, mas também em domićlio, em postos de saúde ou farmácia, desde que realizada por profissionais ou pessoas treinadas ${ }^{8}$. Considera-se que dessa forma se pode evitar complicações como AVC, infarto, insuficiência cardíaca e comprometimento da visão e progressão da doença renal.

Em relação à pergunta sobre quais medidas de pressão arterial são consideradas normais, a maioria dos clientes marcou as opções A e/ou C, embora existisse uma opção que engloba medidas apresentadas por estas opções, ou seja, a letra $\mathrm{D}$ (< que $140 \times 90 \mathrm{mmHg}$ ). Considera-se que a maioria está informada sobre a pressão ideal.

De acordo com as versões das Diretrizes Brasileiras de Hipertensão Arterial ${ }^{9}$, conceitua-se hipertensão arterial os valores de pressão sistólica igual ou superior a $140 \mathrm{mmHg}$ ou de pressão diastólica igual ou superior a $90 \mathrm{mmHg}$.

Conforme relatado previamente, o controle adequado da pressão arterial retarda a progressão da DRC. Nos clientes com doença renal crônica, a pressão arterial deve se manter $<125 / 75 \mathrm{mmHg}$, se apresentarem proteinúria $>$ 1g/24horas, e naqueles com proteinúria $<1 \mathrm{~g} / 24$ horas, a pressão arterial deve se manter $<130 / 80 \mathrm{mmHg}^{10}$.

De acordo com os resultados apresentados na Tabela 2 referente à pergunta sobre o que fazer para manter a pressão arterial dentro do limite normal, $3(5,88 \%)$ clientes responderam somente exercício físico, 49 (96,08\%) clientes marcaram não comer sal, 43 (84,31\%) assinalaram não comer gordura, e 2 (3,92\%) acharam correta a opção tomar remédio apenas quando a pressão estiver alta.

A hipertensão arterial é o fator de risco mais importante para a perda progressiva da função renal, antecipando o início do tratamento dialítico; por sua vez, o controle da hipertensão

\section{Tabela 2}

Hábitos de vida indicados para manter PA normal, conforme respostas dos clientes. Ambulatório de uremia. HUPE/UERJ. Rio de Janeiro, 2005.

\begin{tabular}{l|c|c|c|c|c|c}
\hline \multirow{2}{*}{$\begin{array}{c}\text { Hábitos } \\
\text { de Vida }\end{array}$} & \multicolumn{2}{|c|}{ SIM } & \multicolumn{2}{c|}{ NÃ0 } & \multicolumn{2}{c}{ TOTAL } \\
\cline { 2 - 7 } & $\mathrm{N}$ & $\%$ & $\mathrm{~N}$ & $\%$ & $\mathrm{~N}$ & $\%$ \\
\hline $\begin{array}{l}\text { Só exercício } \\
\text { físico }\end{array}$ & 3 & 5,88 & 48 & 94,12 & 51 & 100 \\
$\begin{array}{l}\text { Não comer sal } \\
\text { Não comer }\end{array}$ & 49 & 96,08 & 2 & 3,92 & 51 & 100 \\
gordura & 43 & 84,31 & 8 & 15,69 & 51 & 100 \\
$\begin{array}{l}\text { Remédio só } \\
\text { qdo a pressão } \\
\text { estiver alta }\end{array}$ & 2 & 3,92 & 49 & 96,08 & 51 & 100 \\
\hline
\end{tabular}


é a intervenção clínica mais importante para retardar a progressão para insuficiência renal crônica terminal ${ }^{11}$.

0 tratamento da hipertensão arterial sistêmica tem como principal objetivo melhorar a qualidade de vida dos clientes e diminuir o risco de complicações e pode ser dividido em tratamento não-medicamentoso e medicamentoso. 0 primeiro baseia-se em modificações do estilo de vida e consiste em: redução da ingestão de sal, prática de exercícios físicos regulares, controle do estresse, abandono do tabagismo e eliminação ou redução do consumo de álcool ${ }^{8,12}$.

Considera-se relevante informar aos clientes, sobre os benefícios do uso contínuo dos medicamentos, que, além da nefroproteção proporcionada pelo uso do inibidor da enzima conversora de angiotensina (IECA), controlam a hipertensão e previnem complicações como pico hipertensivo, AVC, infar to e outras, em decorrência de alguns acreditarem que só devem usar o medicamento quando a pressão arterial está elevada, fato comprovado por este estudo em que 3,92\% dos clientes têm essa prática (Tabela 2). Esses clientes correm o risco de sofrer hipertensão por rebote ocasionada pela interrupção da terapia medicamentosa, além de favorecer a aceleração da DRC.

Para o sucesso do tratamento e manutenção do bemestar é necessário o entendimento dos clientes sobre a importância da combinação de hábitos saudáveis e uso contínuo dos medicamentos.

Quanto à cura da hipertensão arterial, 18 (35,29\%) clientes responderam que acreditam e $33(64,71 \%)$ clientes não acreditam.

\section{Conhecimento dos sujeitos sobre hábitos de saúde e bem-estar}

A resposta dos 51 clientes entrevistados foi unânime ao considerarem a prática de exercício físico importante para a sua saúde; no entanto, apenas 20 (39,22\%) clientes praticam exercício físico: $14(27,45 \%)$ clientes fazem caminhada, 3 $(5,88 \%)$ exercitam-se na bicicleta e $2(3,92 \%)$ realizam caminhada e bicicleta, e $1(1,96 \%)$ cliente pratica dança (Tabela 3). A periodicidade varia de 2 a 6 vezes por semana, e 9 clientes relataram a prática diária (Tabela 3).
A prática de exercício físico regular corresponde a uma das modificações do estilo de vida essencial para o controle da hipertensão arterial, do diabetes e das dislipidemias, além de prevenir complicações e melhorar a auto-imagem e a auto-estima.

0 exercício físico aeróbico ou isotônico regular é capaz de reduzir a pressão arterial, favorecer a perda de peso e/ou reduzir os fatores de risco cardiovascular. Tais exercícios (andar, correr, nadar, andar de bicicleta, futebol, dança e outros) devem ser realizados pelo menos três vezes por semana por um período mínimo de 40 minutos. Clientes com suspeita de doença coronária ou com idade superior a 50 anos devem ser, preliminarmente, submetidos a teste ergométrico. Caso contrário, devem apenas andar ${ }^{8,13}$.

No caso específico de clientes com DRC, a presença de proteinúria pode ser um fator limitante para a realização de determinados exercícios; portanto, esses clientes devem ser avaliados individualmente quanto ao tipo de exerćício que podem realizar.

\section{Conhecimento dos sujeitos sobre complicações em DRC}

Nos dados sobre a questão subjetiva a respeito das possíveis complicações ocasionadas pela dislipidemia, observou-se que a principal complicação citada por 16 clientes foi o aumento do colesterol, 7 clientes falaram infarto, 4 clientes referiram-se à deficiência ou perda da função renal e 16 clientes não souberam responder.

Clientes com DRC apresentam um perfil lipídico tipicamente trombogênico, com elevações dos níveis de triglicérides e reduções do HDL-colesterol, e devem ser considerados como de alto risco para doença cardiovascular, ou seja, apresentam risco equivalente ao dos indivíduos com insuficiência coronariana conhecida. As alterações do metabolismo lipídico na DRC podem ser observadas em fases iniciais do declínio da função renal (TFG $<60 \mathrm{ml} / \mathrm{min})^{14}$.

Indivíduos com hipertrigliceridemia devem ser tratados com modificações do estilo de vida (dieta, abstinência alcoólica, tratamento de hiperglicemia, atividade física), e, caso não haja redução dos níveis até abaixo de $150 \mathrm{mg} / \mathrm{dl}$, a utilização de drogas hipolipemiantes se faz necessária, já o LDL-colesterol deve ser de $100 \mathrm{mg} / \mathrm{dl}_{\text {ou }}$ menos ${ }^{14}$.

\section{Tabela 3}

Distribuição da modalidade e periodicidade de exercícios, realizados pelos clientes. Ambulatório de uremia. HUPE/UERJ. Rio de Janeiro, 2005.

\begin{tabular}{l|c|c|c|c|c|c|c|c|c|c}
\hline Modalidade & \multicolumn{2}{|c|}{ Caminhada } & \multicolumn{2}{|c|}{ Bicicleta } & \multicolumn{2}{c|}{$\begin{array}{c}\text { Bicicleta e } \\
\text { Caminhada }\end{array}$} & \multicolumn{2}{|c|}{ Dança } & \multicolumn{2}{|c}{ Não Praticam } \\
\hline Periodicidade & $\mathrm{N}$ & $\%$ & $\mathrm{~N}$ & $\%$ & $\mathrm{~N}$ & $\%$ & $\mathrm{~N}$ & $\%$ & $\mathrm{~N}$ & $\%$ \\
\hline 3 vezes / sem & 4 & 28,57 & 1 & 33,33 & - & - & 1 & 100 & - & - \\
2 vezes / sem & 3 & 21,42 & - & - & - & - & - & - & - & - \\
4 vezes / sem & 1 & 7,14 & - & - & - & - & - & - & - & - \\
6 vezes / sem & 1 & 7,14 & - & - & - & - & - & - & - & - \\
Diariamente & 5 & 35,71 & 2 & 66,67 & 2 & 100 & - & - & - & - \\
Não praticam & - & - & - & - & - & - & - & - & 31 & 100 \\
\hline Total & 14 & 100 & 3 & 100 & 2 & 100 & 1 & 100 & 31 & 100 \\
\hline
\end{tabular}


De acordo com a análise dos resultados, sobre o tipo de doença ocasionada devido ao não-controle do nível glicêmico, percebeu-se que $41(80,39 \%)$ clientes citaram o diabetes melito. No entanto, $10(19,61 \%)$ clientes não sabiam sobre a patologia ocasionada pelo não-controle glicêmico.

0 DM é uma síndrome decorrente da falta de insulina e/ou da incapacidade da insulina de exercer adequadamente seus efeitos. Caracteriza-se por hiperglicemia crônica com distúrbios do metabolismo dos carboidratos, lipídios e proteínas ${ }^{15}$.

Em relação ao nível de glicemia ideal em jejum, 16 $(31,37 \%)$ clientes assinalaram a opção correta (opção B), 25 $(49,02 \%)$ clientes não responderam e os demais assinalaram opções incorretas. Nota-se que predominou a clientela desinformada sobre o nível ideal da glicemia capilar ou plasmática em jejum, considerada uma das medidas primordiais para o controle do DM. Recorda-se que nessa pesquisa foram incluídos clientes com e sem diabetes melito.

A medida da glicose plasmática em jejum, pela sua praticidade, é o procedimento básico empregado para fazer o diagnóstico de DM. Níveis de glicemia maior que $110 \mathrm{mg} / \mathrm{dl}$ e menor que $126 \mathrm{mg} / \mathrm{dl}$ são categorizados como glicemia de jejum alterada, e valor maior ou igual a $126 \mathrm{mg} / \mathrm{dl}$ é diagnóstico para diabetes melito ${ }^{15}$.

Em clientes com nefropatia diabética, são desejáveis valores de glicemia de jejum entre $80 \mathrm{mg} / \mathrm{dl} \mathrm{e} 120 \mathrm{mg} / \mathrm{d}{ }^{10} .0$ controle rigoroso da glicemia é fundamental, haja vista que o controle glicêmico em clientes com nefropatia clínica, associado a um controle dos níveis pressóricos, pode reduzir a perda de função renal.

Conforme resultados da Tabela 4 referentes aos cuidados que o cliente deve tomar para o controle do diabetes melito, predominou o número de acertos referentes às opções de $1 \mathrm{a}$ 4. Ressalte-se a maioria de $47(92,16)$ clientes que responderam afirmativamente à opção 2, enquanto todos 51 $(100 \%)$ responderam que não se deve comer doces.

\section{Tabela 4}

Hábitos de vida indicados para o controle glicêmico, conforme respostas dos clientes. Ambulatório de uremia. HUPE/UERJ. Rio de Janeiro, 2005.

\begin{tabular}{l|c|c|c|c|c|c}
\hline \multirow{2}{*}{$\begin{array}{l}\text { Hábitos } \\
\text { de Vida }\end{array}$} & \multicolumn{2}{|c|}{ SIM } & \multicolumn{2}{c|}{ NÃ0 } & \multicolumn{2}{c}{ TOTAL } \\
\cline { 2 - 7 } & $\mathrm{N}$ & $\%$ & $\mathrm{~N}$ & $\%$ & $\mathrm{~N}$ & $\%$ \\
\hline $\begin{array}{l}\text { Verificar } \\
\text { glicemia capilar } \\
\text { diariamente }\end{array}$ & 40 & 78,43 & 11 & 21,57 & 51 & 100 \\
$\begin{array}{l}\text { Usar } \\
\text { medicamentos } \\
\text { prescritos }\end{array}$ & 47 & 92,16 & 4 & 7,84 & 51 & 100 \\
$\begin{array}{l}\text { Seguir dieta } \\
\text { prescrita }\end{array}$ & 46 & 90,2 & 5 & 9,8 & 51 & 100 \\
$\begin{array}{l}\text { Fazer exercícios } \\
\text { regulamente }\end{array}$ & 42 & 82,35 & 9 & 17,65 & 51 & 100 \\
$\begin{array}{l}\text { Comer doces } \\
\text { todos 0s dias }\end{array}$ & - & - & 51 & 100 & 51 & 100 \\
\hline
\end{tabular}

Entretanto, considerando o somatório de 29 (56,14\%) sujeitos que responderam incorretamente, o fato é significativo para nos certificar de que todos precisam ser orientados sobre a importância da combinação de todos os cuidados para que 0 controle do diabetes melito seja eficiente.

0 tratamento para o controle do DM inclui as seguintes estratégias: educação, modificações do estilo de vida que compreendem a suspensão do fumo, abandono da bebida alcoólica, realização de atividade física e reorganização dos hábitos alimentares, e uso de medicamentos conforme orientação médica.

Quanto à cura do DM, $15(29,41 \%)$ clientes responderam que acreditam, e $34(66,67 \%)$ clientes não acreditam.

As consequêencias do DM a longo prazo incluem danos, disfunção e falência de vários órgãos, especialmente rins (nefropatia), olhos (retinopatia), nervos (neuropatia), coração e vasos sangüíneos (micro e macroangiopatia). Essas complicações podem surgir precocemente caso não haja 0 controle da doença. A complicação mais conhecida e citada por 18 clientes é o comprometimento ou perda da visão; em segundo lugar, 11 clientes citaram a amputação de membros e/ou morte.

Identificou-se que $38(74,51 \%)$ clientes assinalaram associação da anemia e doença renal crônica e 38 (74,51\%) clientes consideraram a ocorrência da doença óssea na vigência da doença renal crônica. Dois $(3,92 \%)$ clientes afirmaram que não ocorre anemia na DRC e $11(21,57 \%)$ clientes não sabiam responder. Quanto à doença óssea, $3(5,88 \%)$ clientes falaram que não ocorre a doença óssea na DRC e $10(19,61 \%)$ clientes não sabiam a resposta (Tabela 5).

\section{Tabela 5}

Ocorrência de anemia e/ou doença óssea em pessoas com DRC, de acordo com as respostas dos clientes. Ambulatório de uremia. HUPE/UERJ. Rio de Janeiro, 2005.

\begin{tabular}{l|c|c|c|c}
\hline \multirow{2}{*}{$\begin{array}{l}\text { Ocorrência de } \\
\text { anemia }\end{array}$} & \multicolumn{2}{|c|}{ Anemia } & \multicolumn{2}{c}{ Doença óssea } \\
\cline { 2 - 5 } e doença óssea & $\mathrm{N}$ & $\%$ & $\mathrm{~N}$ & $\%$ \\
\hline Sim & 38 & 74,51 & 38 & 74,51 \\
Não & 2 & 3,92 & 3 & 5,88 \\
Não sabe & 11 & 21,57 & 10 & 19,61 \\
\hline Total & 51 & 100 & 51 & 100 \\
\hline
\end{tabular}

A anemia e a doença óssea são algumas das principais complicações surgidas no curso da DRC, particularmente quando a $\mathrm{FG}$ diminui a valores $<60 \mathrm{ml} / \mathrm{min} / 1,73 \mathrm{~m}^{2}{ }^{16}$. Portanto, considera-se importante a orientação dos clientes quanto a essas complicações para que se sintam motivados para 0 autocuidado, haja vista que alguns deixam de seguir as orientações por desconhecerem as complicações da doença e os benefícios de seguir as orientações para o controle dela.

A anemia ocorre em todos os clientes com DRC, inicialmente devido à deficiência da absorção intestinal de ferro e posteriormente devido à deficiência de eritropoetina, haja vista que uma das funções do rim é endócrina, em que o mesmo é responsável pela produção da eritropoetina. Em clientes com 
DRC acompanhados pelo tratamento conservador, pode ocorrer a resistência à ação da eritropoetina, ou seja, os níveis séricos de eritropoetina são normais, porém a medula óssea não responde adequadamente a ela ${ }^{17}$.

A anemia estigmatiza o cliente, conferindo-lhe um aspecto de doente, além de provocar também incapacidade física e mental, prejudicando de maneira importante sua recuperação social, sendo responsável pela redução da qualidade de vida ${ }^{18}$.

Desse modo, o principal objetivo do tratamento da anemia na doença renal consiste na promoção do restabelecimento social do cliente, evitando complicações e proporcionando-lhe melhor qualidade de vida.

Os rins também têm importante papel na manutenção das quantidades adequadas de fósforo e cálcio no organismo, pois esses minerais juntos ajudam a manter os ossos saudáveis. No cliente com DRC, como os rins não funcionam adequadamente, o equilíbrio entre esses dois minerais está prejudicado. Assim, a eliminação de fósforo pela urina diminui, acumulando-se no sangue.

Altos níveis de fósforo no sangue facilitam a retirada de cálcio dos ossos. Essa situação de desequilíbrio dos dois minerais pode levar à doença óssea, que provoca dores, enfraquecimento e quebra dos ossos se não tratada adequada e precocemente. Dessa forma, o controle dos níveis de fósforo e cálcio é o primeiro passo para prevenir e tratar essas condições.

Geralmente, a primeira estratégia de controle dos níveis de fósforo e cálcio é a dieta planejada pelo nutricionista. No entanto, quando, apesar da restrição dietética, não houver o controle desses minerais, torna-se necessária a prescrição médica de quelantes de fósforo, medicamentos ingeridos junto com a alimentação para evitar a absorção intestinal do fósforo e conseqüente equilíbrio do cálcio, haja vista que o aumento dos níveis séricos do fósforo ocasionam uma queda dos níveis séricos de cálcio².

Referente ao comprometimento dos rins pela hipertensão arterial sistêmica, 49 (96,08\%) clientes referiram que ocorre e apenas 2 (3,92\%) clientes não souberam responder.

Quanto ao acometimento renal pelo diabetes, 40 $(78,43 \%)$ clientes afirmaram que pode ocorrer 0 comprometimento, $4(7,84 \%)$ clientes falaram que não ocorre e $7(13,73 \%)$ clientes não souberam responder .

Aproximadamente $25 \%$ dos pacientes que são submetidos à diálise crônica e que necessitam de transplante renal têm como única causa da insuficiência renal a hipertensão arterial. Esses dados adquirem ainda maior importância quando a hipertensão está associada ao diabetes melito ${ }^{19}$.

A hipertensão arterial compromete principalmente as estruturas vasculares renais (artérias, arteríolas e capilares glomerulares). Entretanto, são nas arteríolas e glomérulos que ocorrem as conseqüências mais sérias da hipertensão arterial sobre os rins. A parede das arteríolas renais sofre espessamento das camadas muscular e elástica, reduzindo o fluxo efetivo para o glomérulo e túbulo interstício.

0 diabetes melito constitui-se hoje na primeira causa de DRC em diversos países e na segunda causa no Brasil. A nefropatia diabética acomete de 30 a $40 \%$ dos indivíduos com DM tipo 1 e 10 a $40 \%$ daqueles com o tipo
2, sendo os glomérulos as principais estruturas renais acometidas pelo diabetes melito ${ }^{20}$.

A partir dessas referências, torna-se evidente 0 comprometimento renal pela hipertensão e pelo diabetes, sendo estes considerados as principais causas da doença renal crônica. Ressalta-se a importância da prevenção secundária por meio do controle dos níveis pressóricos e glicêmicos, e dessa forma considera-se a educação desses clientes para o autocuidado a ferramenta ideal para incentivá-los à adesão ao tratamento. Tudo isso tem a finalidade de minimizar as conseqüências da doença já instalada e adiar o ingresso desses clientes em uma das terapias de substituição renal, além de prepará-los para que ingressem em condições clínicas adequadas.

\section{Conhecimento dos sujeitos sobre função renal e ocorrência da DRC}

Quanto às funções dos rins, a Tabela 6 expõe que 26 (50,98\%) clientes escolheram a opção A, considerada correta (filtração, regulação de substâncias necessárias ao organismo e produção de hormônios). Os demais assinalaram as opções incorretas; entre eles, $14(27,45 \%)$ clientes optaram pela letra $B$, a qual dizia que a função dos rins é somente filtração do sangue, e $4(7,84 \%)$ clientes assinalaram a opção C (somente eliminação de substâncias nocivas ao organismo).

Tabela 6

Conhecimento dos clientes acerca das funções dos rins. Ambulatório de uremia. HUPE/UERJ. Rio de Janeiro, 2005.

\begin{tabular}{l|c|c}
\hline Funções dos rins & N & $\%$ \\
\hline $\begin{array}{l}\text { A) Filtração, regulação de } \\
\text { substâncias necessárias } \\
\text { ao organismo e } \\
\text { produção de hormônios. }\end{array}$ & 26 & 50,98 \\
$\begin{array}{l}\text { B) Somente filtração do } \\
\text { sangue }\end{array}$ & 14 & 27,45 \\
$\begin{array}{l}\text { C) Somente eliminação de } \\
\text { substâncias nocivas ao } \\
\text { organismo }\end{array}$ & 4 & 7,84 \\
Não sabe & 7 & 13,73 \\
\hline Total & 51 & 100 \\
\hline
\end{tabular}

0 rim possui duas funções: função endócrina e homeostática ${ }^{21}$

- Função endócrina: consiste na produção de hormônios como renina, 1,25 diidroxicalciferol e eritropoetina ${ }^{21}$.

- Função homeostática: manutenção de um volume hídrico adequado, a qual ocorre em função da excreção de água e solutos; regulação da concentração de íons como sódio, potássio, cloreto, bicarbonato, magnésio e fosfato; manutenção do pH, contando também com o auxílio do 
pulmão; manutenção da concentração adequada de metabólitos, devida à capacidade de reabsorção presente nos túbulos renais; eliminação de produtos do metabolismo como uréia, ácido úrico e timina, além de drogas ou substâncias tóxicas presentes nos alimentos, em função da capacidade de excreção renal ${ }^{21}$.

Perguntou-se quando a doença renal ocorre, e 37 (72,55\%) clientes optaram pela resposta correta, opção A; no entanto, os demais clientes demonstraram desconhecimento a respeito deste assunto.

A doença renal crônica caracteriza-se pela incapacidade dos rins de remover os produtos de degradação metabólica do corpo ou de realizar as funções reguladoras. As substâncias normalmente eliminadas pela urina ficam retidas no sangue em conseqüência da excreção renal comprometida e levam a uma ruptura das funções endócrinas e metabólicas, bem como a distúrbios hidroeletrolíticos e acidobásicos ${ }^{22}$.

\section{CONSIDERAÇÕES FINAIS}

Alcançando-se o objetivo referente à pré-avaliação, identificaram-se o déficit e o conhecimento dos clientes acerca da hipertensão arterial sistêmica e do diabetes melito (inclusive a crença na cura dessas patologias), conhecimento acerca das complicações da dislipidemia, modalidade de exercício físico praticada, atividade de lazer desenvolvida, hábitos de higiene corporal, conhecimento acerca das funções dos rins, da anemia e doença óssea associadas à DRC. Concluiu-se, através dos dados produzidos na pré-avaliação, que, para os clientes, as principais complicações da HAS são AVC, DRC e cardiopatia.

Apesar de os clientes estarem cientes da não-ingestão de gordura e sal para o controle da pressão arterial, identificouse um déficit de autocuidado, haja vista que poucos clientes afirmaram só tomar remédio quando a pressão estava alta,

\section{Referências}

1. Brienza AM, Mishimia SM, Frederico P, Clápis MJ. Grupo de reeducação alimentar: uma experiência holística em saúde na pespectiva familiar. Rev Bras Enferm 2002 nov /dez; 55(6): 697-700.

2. Lima EX.Atenção de enfermagem em nefrologia clínica e cirúrgica e o cuidar dialógico em transplante renal. In: Santos I, Figueiredo NMA, Padilha MICS, Cupello AJ, Souza SROS, Machado WCA. Enfermagem assistencial no ambiente hospitalar: realidade, questões, soluções. São Paulo (SP): Atheneu; 2004. p.311-40.

3. Gauthier J, Hirata M. A enfermeira como educadora. In: Santos I, Figueiredo NMA, Duarte MJRS, Sobral VRS, Marinho AM. Enfermagem fundamental: realidade, questões, soluções. São Paulo(SP): Atheneu; 2001. p.123-41.

4. Cesarino CB, Casagrande LDR. Paciente com insuficiência renal crônica em tratamento hemodialítico: atividade educativa do enfermeiro. Rev Latino-Am Enfermagem 1998; 6 (4): 31-40.

5. Freire P. Pedagogia do oprimido. 36. ed. Rio de Janeiro(RJ): Paz e Terra; 2003. enquanto a minoria considerou somente o exercício físico importante no controle da pressão arterial.

Quanto aos hábitos de saúde e lazer, conclui-se que todos consideraram o exercício físico importante, embora poucos o praticassem, sendo a caminhada e a bicicleta, ou ambas, as modalidades mais praticadas.

Evidenciou-se que um menor percentual de clientes considerou a verificação regular da glicemia capilar e o exercício físico importantes para o controle do DM.

A maioria dos clientes demonstrou estar ciente do comprometimento renal pelo DM e pela HAS, bem como da ocorrência da anemia e doença óssea na DRC.

Apenas a metade dos clientes respondeu corretamente sobre todas as funções dos rins, apesar da predominância daqueles que acertaram sobre a origem da DRC.

Considera-se que é preciso que os clientes tenham consciência do seu potencial para se autocuidar, pois partese do princípio de que as pessoas não estão por completo doentes, dentro delas existe um núcleo saudável. Estes sujeitos devem ser incentivados para perderem a noção de passividade e tornarem-se protagonistas do seu próprio cuidado, este é um ato de cidadania.

A educação à saúde é um direito de cidadania, muitas vezes não garantido pela instituição de saúde por questões financeiras, políticas e até por falta de conhecimento dos profissionais sobre sua importância para favorecer a adesão do cliente ao tratamento, garantindo-Ihes qualidade de vida, além de reduzir os custos do sistema de saúde ${ }^{23}$.

Entre os resultados, observou-se o conhecimento dos clientes sobre seus próprios limites na escolha e adesão das terapêuticas médica, nutricional e de enfermagem, fato que leva à reflexão sobre o imperativo de se buscar entender o cotidiano do cliente e seus modos de viver a vida e sobreviver com a DRC. 0 ensino do autocuidado, portanto, deve valorizar os saberes, as vozes, a cultura e as forças de luta pela vida das pessoas, conduzindo-as à sua autonomia em questões de bem-estar e bem viver .

6. Pereira MG. Epidemiologia: teoria e prática. Rio de Janeiro(RJ): Guanabara Koogan; 1995.

7. Heimann JC, Krieger JE, Zatz R. Fisiopatologia da hipertensão arterial. In: Zatz R. Fisiopatologia renal. São Paulo(RJ): Atheneu; 2002. p. 173-88.

8. Almeida FA, Rodrigues CIS. Hipertensão arterial primária. In: Riella MC. Princípios de nefrologia e distúrbios hidroeletrolíticos. $4^{\mathrm{a}}$ ed. Rio de Janeiro(RJ): Guanabara Koogan; 2003. p.730-56.

9. IV Diretrizes Brasileiras de Hipertensão Arterial. Sociedade Brasileira de Hipertensão. Sociedade Brasileira de Cardiologia. Sociedade Brasileira de Nefrologia. Campos do Jordão(SP); 2002.

10. Bregman R. Prevenção da progressão da doença renal crônica (DRC). In: Sociedade Brasileira de Nefrologia. Diretrizes de condução de doença renal crônica. [on-line] [citado 27 de julho de 2004.Disponível em: http://www.sbn.org.br.

11. Pereira ERS, Pascoal IF, Mion Junior D. Hipertensão arterial e doença renal parenquimatosa. In: Riella MC. Princípios de nefrologia e distúrbios hidroeletrolíticos. $4^{\mathrm{a}}$ ed. Rio de Janeiro(RJ): Guanabara Koogan; 2003. p. 769-86. 
12. Tavares A, Ribeiro AB, Rodrigues CJO. Hipertensão arterial: diagnóstico e tratamento. In: Ajzen H, Schor N. Guia de medicina ambulatorial e hospitalar de nefrologia. $2^{\mathrm{a}}$ ed. São Paul(SP): Manole; 2005. p. 171-82.

13. Berlin J.A, Colditz GA. A meta-analysis of physical activity in the prevention of coronary heart disease. Am J Epidemiol 1990; 132: 612-28.

14. Batista M, Oliveira CJR. Alterações metabólicas. In: Sociedade Brasileira de Nefrologia. Diretrizes de condução de doença renal crônica. [on-line] [citado 27 julho 2004].Disponível em: http://www.sbn.org.br.

15. Gross JL, Ferreira SRG, Franco LJ, Schimidt MI, Motta DG, Quintão E. Consenso: diagnóstico e classificação do diabetes melito e tratamento do diabetes melito tipo 2. Arq Bras Endocrinol Metab 2000; 44(4):1-32.

16. Batista LKC, Pinheiro HS, Fuchs RC, Oliveira T, Belchior FJE, Galil AGS. Manuseio da doença renal crônica em pacientes com hipertensão e diabetes. J Bras Nefrol 2005; 27(1): 8-14.

17. Mcgonigle RJ, Wallin JD, Shadduck RK et al: Erythropoietin deficiency na inhibition of erythropoiesis in renal insufficiency. Kidney Int 1984; 25: 437-44.

18. Abensur H, Alves MAR. Diretrizes da Sociedade Brasileira de Nefrologia para a condução da anemia na insuficiência renal crônica. J Bras Nefrol 2000; 22 (5):1-3.

19. Almeida FA, Rodrigues CIS. Hipertensão arterial primária. In: Riella MC. Princípios de nefrologia e distúrbios hidroeletrolíticos. $4^{\mathrm{a}} \mathrm{ed}$. Rio de Janeiro(RJ): Guanabara Koogan; 2003. p.730-56.

20. Kohlmann Jr 0, Zanella MT. Nefropatia diabética: diagnóstico e tratamento. In: Ajzen H, Schor N. Guia de medicina ambulatorial e hospitalar de nefrologia. $2^{\text {a }}$. ed. São Paulo(SP): Manole; 2005. p.359-366.
21. Boim MA, Teixeira VPC, Schor N. Rim e compostos vasoativos. In: Zatz R. Fisiopatologia renal. São Paulo(SP): Atheneu; 2002. p. 21-39.

22. Smeltzer SC, Bare BG. Tratamento de pacientes com distúrbios urinários e renais. In: Smeltzer SC. Brunner\& Suddarth: Tratado de Enfermagem Médico-Cirúrgica 9a ed. Rio de Janeiro(RJ): Guanabara Koogan; 2002 .v. 3 p. 1086-1134.

23. Pacheco GS. 0 ensino do autocuidado junto a clientes com doença renal crônica em tratamento conservador: estudo epidemiológico e sociopoético [dissertação de mestrado]. Rio de Janeiro (RJ): Faculdade de Enfermagem/UERJ; 2005.

24. Santos I, Figueiredo NMA. A enfermagem como instituição hospitalar. In: Santos I, Figueiredo NMA, Padilha MICS, Cupello AJ, Souza SROSS, Machado WCA. Enfermagem assistencial no ambiente hospitalar. Rio de Janeiro(RJ): Atheneu p. 93-104.

\section{Sobre as Autoras}

\section{Gilvanice de Sousa Pacheco}

Mestre em Enfermagem (FENF/UERJ). Especialista em Enfermagem em Nefrologia (Universidade Gama Filho/RJ). Especialista em Enfermagem Clínico-Cirúrgica (UFMA) e Saúde Pública (UNAERP). Email: gilvanicepacheco@yahoo.com.br

\section{Iraci dos Santos}

Doutora em Enfermagem. Profa Titular da Universidade do Rio de Janeiro (UERJ). Professora do Programa de Mestrado em Enfermagem da UERJ.

\section{Rachel Bregman}

Doutora em Nefrologia. Profa da Disciplina de Nefrologia da Faculdade de Medicina da UERJ. 